\title{
Does adding a spatial component to a herbicide resistance population model improve understanding and predictions of the build-up of herbicide resistance over time?
}

\author{
Gayle J. Somerville $^{\mathrm{a}}$ and Michael Renton ${ }^{\mathrm{a}}$ \\ ${ }^{a}$ Australian Herbicide Resistance Initiative, School of Plant Biology, \\ University of Western Australia, Crawley WA 6009 Australia \\ Email: gayle.somerville@research.uwa.edu.au
}

\begin{abstract}
Weeds are patchy, and these patches can be dynamic. A model of weed population dynamics and herbicide resistance evolution that includes a spatial component can allow for more realistic modelling of important spatial heterogeneity. Local variability in genetic mutations and frequencies and density/yield interactions, and the stochastic nature of genetic drift and migration can be included. This can lead to new insights and understanding and an increase in grower and researcher confidence in model predictions.

One useful way to increase the transparency, accuracy and usefulness of an herbicide resistance model is through increasing the realism whereby biological processes are represented in the model. To model plant interactions occurring uniformly across a whole field of weeds is unrealistic; biological interactions and dispersal are typically local scale, likely causing the patches of weeds that occur in fields. The aim here was therefore to include a spatial component in an existing model by dividing a single homogeneous population into many individual sub-populations in areas defined as 'sections'. This allowed us to incorporate both natural and anthropogenic pollen and seed spread within and between sections into the new SOMER model (Spatially Orientated Model of Evolutionary Resistance).

This new spatial model was developed by dividing a single homogenous population into many smaller subpopulations. These sub-populations were spread to cover the central area (1.1664 ha) of a larger homogeneous field. Pollen and seed spread between sub-populations (and pollen from further afield) was added each year to simulate realistic conditions. This new SOMER model was then compared with an identically parameterized non-spatial model of a single homogeneous population of the same size (1.1664 ha).

The spatial model has already provided new insights. For example, earlier non-spatial models predict that the number of resistant weeds in a field typically increases by a constant factor each year, at least until densities become high. However preliminary results from this spatial model indicate that resistance builds up more slowly when spatial factors are accounted for, due the need for the resistance genes to spread through the population. Additional studies evaluating the importance of pollen dispersal and the movement of seed by machinery are currently being examined.
\end{abstract}

Keywords: Herbicide resistance, spatial modelling, SOMER, agriculture 
Somerville and Renton, Does adding a spatial component to a herbicide resistance population model improve understanding and predictions of the build-up of herbicide resistance over time?

\section{INTRODUCTION}

Today's farming industry faces the serious issue of declining weed control due to evolved resistance to herbicides. Many methods have been proposed to delay the build-up of herbicide resistance, such as changing fertilizer rates or annual rotation strategies (Norsworthy et al., 2012), and new discoveries are extending farmers' options. However despite researchers' best efforts, farmers are often slow to adopt new strategies and many farmers are not using best practice (Walsh, Newman, \& Powles, 2013). Difficulties in choosing strategies to implement on their farm are compounded by lack of situation-specific knowledge of the relative benefits of different strategies; the most effective combinations of strategies will most likely vary between different farming situations. Long-term multi-faceted field trials are slow, site-specific and expensive.

To compound these difficulties agriculturalists are sometimes reluctant to invest in new non-herbicide strategies. Many farmers are simply waiting for new herbicides to be developed, and in addition farmers have concerns that costly efforts to control herbicide resistance build-up within their farms may be thwarted by movement onto the farm of resistant seed and/or pollen from neighbouring farms, despite some evidence to the contrary (Malone, Boutsalis, Baker, \& Preston, 2014). Patches of herbicide resistant weeds on individual farms can develop very quickly, and the specific source of resistant weeds is seldom known.

Spatial modelling is predicted to give timely, more realistic results. In addition these more realistic results will allow better visualization with an aim of increasing understanding by both non-modelling researchers and farmers of the importance of targeting best practices to minimize the build-up of herbicide resistance, and the accompanying increase in weed numbers.

\section{MODEL DYNAMICS OVERVIEW}

This study compares two simulations of the evolution of herbicide resistance in an annual weed growing in a typical winter cropping program in a Mediterranean-type climate. A new Spatially Orientated Model of Evolutionary Resistance (SOMER) model was compared to a simpler homogeneous model using identical population parameters. These two models both represent single gene resistance, while incorporating features from the existing "Polygenic Evolution of Resistance To Herbicides" (PERTH) model (Renton, 2009; Renton et al., 2011). The models are implemented in the ' $R$ ' language ( $R$ Core Team, 2014). Calculations of competition, seed production and seed genotype were conducted stochastically for each year of the simulations. These calculations were carried out for each genotype, with the equations used sourced from Renton et al. (2011).

In the SOMER model the central 1.17 ha area was split into one-metre square sections, each containing a separate sub-population. These sub-populations were modelled separately each year, except at pollination and seed-fall, when mixing of genetic material through seed and pollen dispersal occurred between subpopulations. Squares were chosen as the best section shape as they align with activities such as seeding and harvest. The movement of pollen and seed between these subpopulations in the SOMER model is illustrated by the dotted lines in Figure 1, whereas the simpler homogenous model it is compared to does not include this interaction.

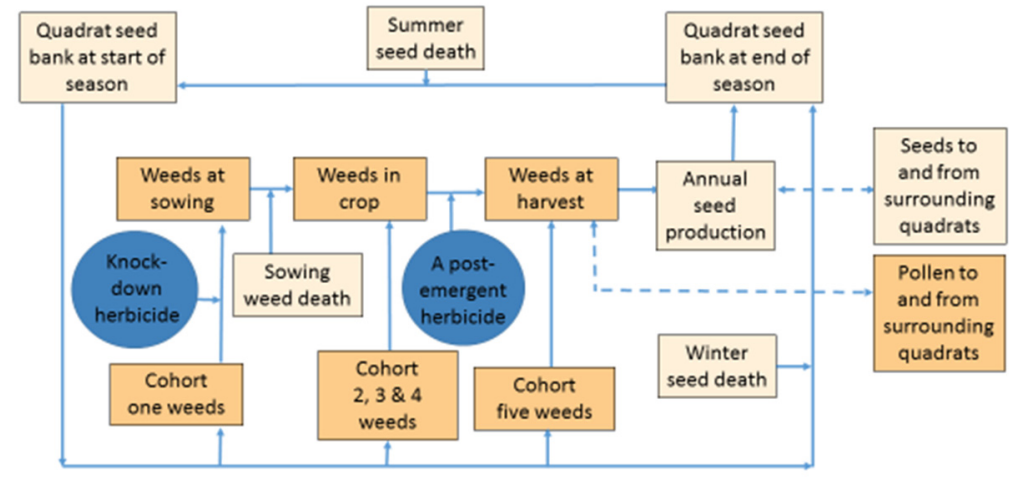

Figure 1. Representation of the lifecycle of managed L. rigidum weeds growing in a Western Australian wheat crop and modelled in both the nonspatial and SOMER models. 
Somerville and Renton, Does adding a spatial component to a herbicide resistance population model improve understanding and predictions of the build-up of herbicide resistance over time?

\section{PARAMETRIZATION}

The simulations in this study were based on a single well-studied weed species, annual ryegrass (Lolium rigidum), within a wheat crop (Tritium spp). Annual ryegrass (L. rigidum) is a widespread obligateoutcrossing and genetically diverse species, with the majority of populations in Western Australia containing some level of herbicide resistance to many ACCase- and AHAS-inhibiting herbicides (Boutsalis, Gill, \& Preston, 2012; Llewellyn, D'Emden, Owen, \& Powles, 2009; Owen, Martinez, \& Powles, 2014). Parameters used are based on RIM (Lacoste \& Powles, 2014) and PERTH (Renton, 2011) (Table 1). Unverified parameters were calibrated by adjusting within biologically reasonable limits (Lacoste \& Powles, 2014; Renton, 2011) to give realistic annual weed numbers at harvest over time, in the absence of resistance. The density and species of crop, and the type of weed will affect the distance of weed seed spread (Humston, Mortensen, \& Bjornstad, 2005), making the specific estimations used here both weed and crop specific. However, we expect the general conclusions should be more far-reaching.

Table 1. Parameter values used in the model runs in this study

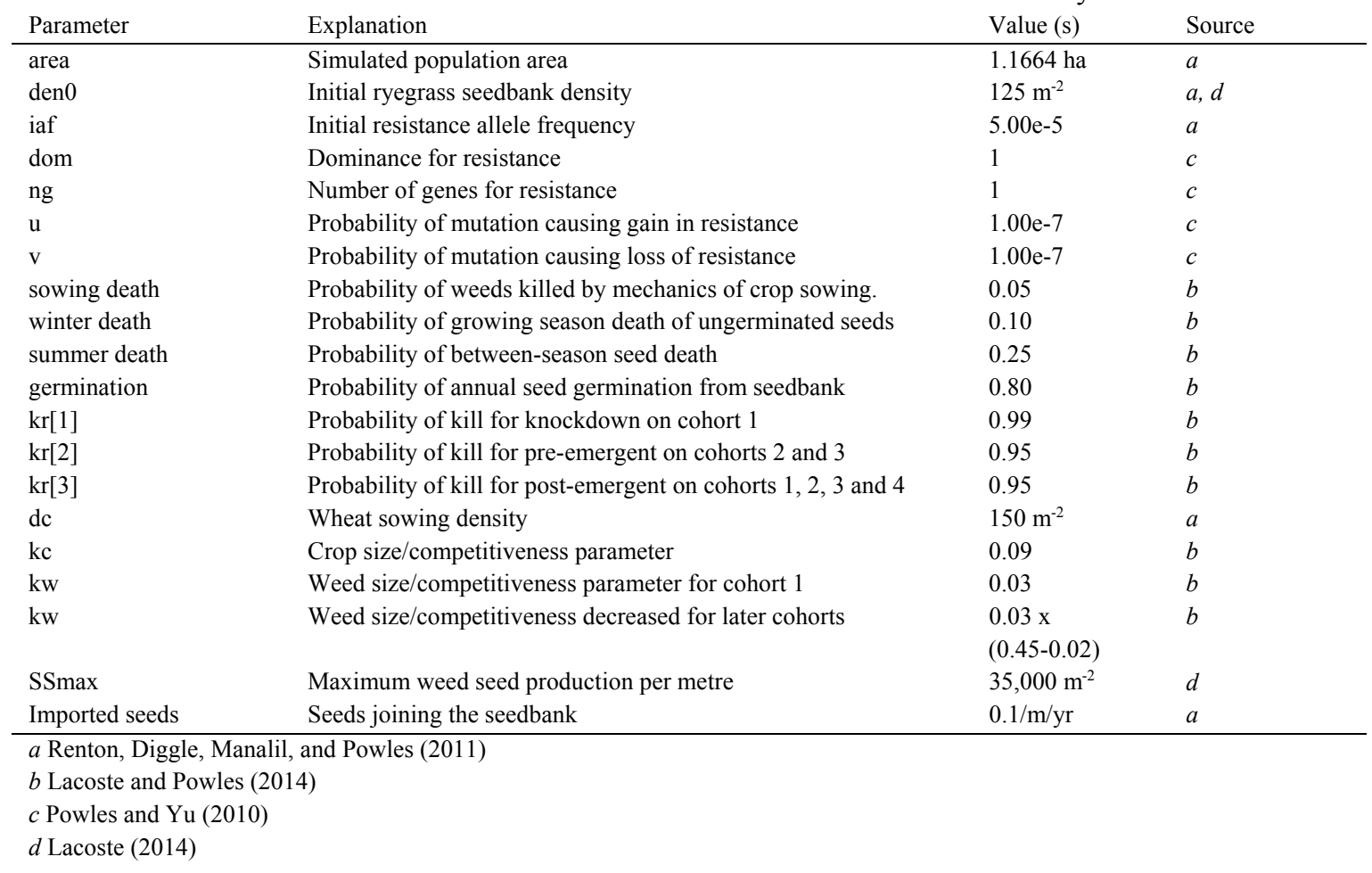

\subsection{Maximum L. rigidum density}

The maximum density of $L$. rigidum per section was set at 3000 full size equivalent adult plants per metre square. Density in subsequent generations was limited when weed numbers exceeded $3000 \mathrm{~m}^{-2}$ by lowering the fitness of weeds in the later emerging cohorts to one percent of its initial value. Due to the stochastic nature of seed production (Renton, 2009) this insured that stochastic population numbers per section were maintained.

\section{SPATIAL COMPONENTS}

The 1.1664 hectare area and its simulated population were divided into sub-populations contained within sections, with each sub-population assigned to a specific section. The calculations of weed and crop competition, seed production and seed genotype were carried out for each sub-population in the SOMER model; for each genotype, identically to in the non-spatial model.

The spatial model also included weed pollen and seed spread sub-models, enable us to address our specific research question on the effects of adding spatial realism to an evolutionary weed resistance population model. In the SOMER simulation model, pollen and seed spread rates declined with distance from the source. A larger environment, outside the spatially modelled 1.17 hectare area, but still part of the wheat field, was included 
Somerville and Renton, Does adding a spatial component to a herbicide resistance population model improve understanding and predictions of the build-up of herbicide resistance over time?

into the SOMER pollen spread sub-model by extending the area available to source pollen beyond the defined $1.17 \mathrm{ha}$ area. The aim was to ensure that every sub-population (including those near the edge of the $1.17 \mathrm{ha}$ study area) had access to similar pollen levels. This larger area was incorporated into the spatial sub-model of pollen flow based on distance from the home section, with the assumption that weeds in the un-modelled areas were homozygous susceptible and occurred in similar densities (to the investigated area) across a wider (unmodelled) area of field.

\subsection{Spatial pollen spread sub-model}

The decline in pollination probability due to distance from the source was based on data from Knowles and Ghosh (1968). An analysis was conducted on their data of the seed percentages and the location of each of the local and external plants in the two neighbouring plots ( 1440 plants in a 45 by $16 \mathrm{yd}$. area). A Weibull model gave the best fit to the data (error $=0.002$ ), and yielded the followed equation.

average percent locally fertilised seeds $=\frac{\sum_{i=1}^{720} \mathrm{~A}-\mathrm{D} e^{-e^{l} \text { distance }_{i}^{p}}}{\sum_{i=1}^{1439} \mathrm{~A}-\mathrm{D} e^{-e^{l} \text { distance }} e_{i}^{p}}$

After the data in Knowles and Ghosh (1968) was adjusted to remove $8 \%$ self fertilised seeds, the parameters were: Asymptote $(A=0)$, Drop $(D=-1)$, Natural logarithm $(l=1.9304)$ and Power $(p=0.2294)$. These parameters were then used to yield the pollination probabilities for each plant, based on the distance between each home section and the pollen source sections.

pollen proportion per plant $=\quad \frac{e^{-e^{l}\left(\frac{\text { distance }_{0}}{0.9136}\right)_{i}^{p}}}{\sum_{i=1}^{11664} e^{-e^{l}\left(\frac{d i s t a n c e}{0.9136}\right)_{i}^{p}}}$

These results are explained graphically in Figure 2.

A larger environment, outside the spatially modelled 1.1664 hectare area, but still part of the wheat field, was included into the SOMER pollen spread sub-model by extending the area available to source pollen beyond the defined $1.17 \mathrm{ha}$ area. The aim was to ensure that every section (including those near the edge of the 1.1664 ha study area) had access to similar pollen levels. This larger area was incorporated into the spatial sub-model of pollen flow based on distance from the home section, with the assumption that weeds in the un-modelled areas were homozygous susceptible and occurred in similar densities (to the investigated area) across a wider (un-modelled) area of field.
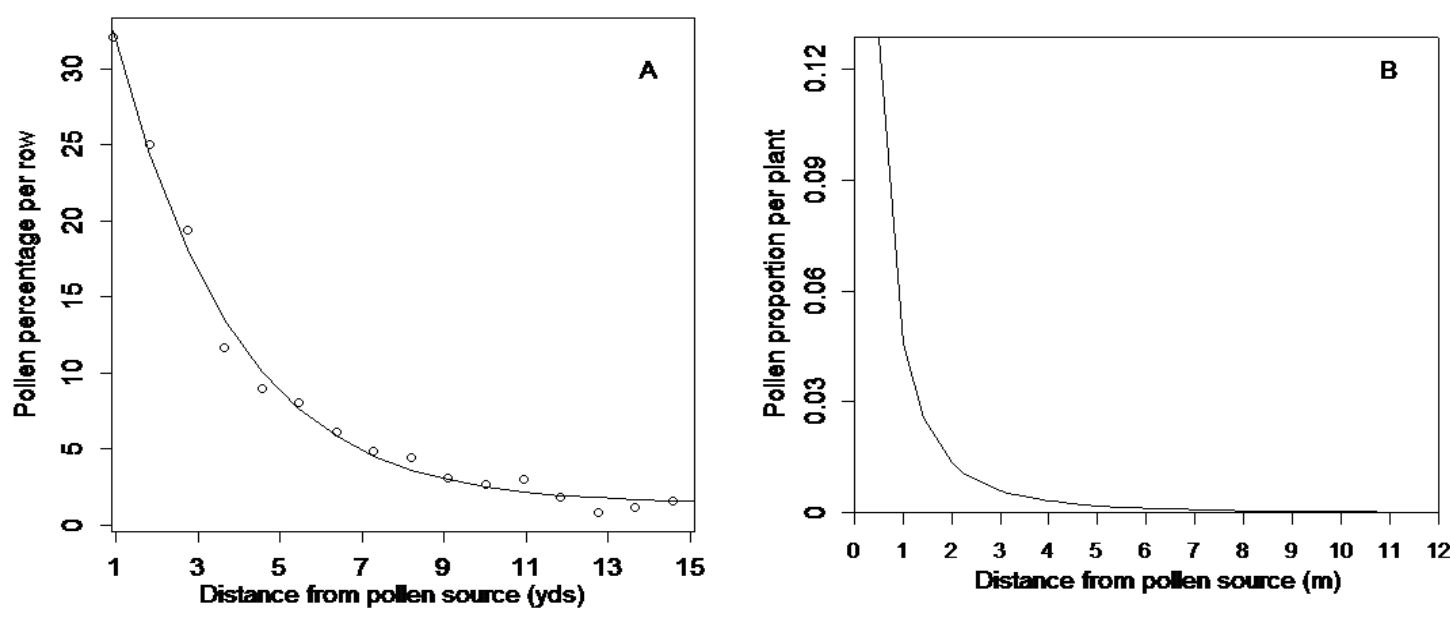

Figure 2. Fitting a fat-tailed Weibull curve to individual plant pollen spread data in Knowles and Ghosh

(1968). The Weibull curve in figure A is constructed using a best-fit parameter estimation for the distances to each pollen producing plant in the test area (Equation1). The parameters calculated in figure $2 \mathrm{~A}$ are then used to calculate the pollen proportion for individual plants in figure $2 \mathrm{~B}$. 
Somerville and Renton, Does adding a spatial component to a herbicide resistance population model improve understanding and predictions of the build-up of herbicide resistance over time?

\subsection{Seed dispersal into adjoining sections}

Wind, insects and farming activities were assumed to spread weed seeds radially from each sub-population into sub-populations in surrounding sections. The dispersal calculations therefore reflected inter-section seed spread by all methods; from spring weed seed shed until autumn germination. This type of seed spread is assumed to be small due to trash left by commonly used conservative harvest methods, (Aguiar \& Sala, 1997; Fenner, 1985) and is therefore confined to the eight sections immediately surrounding the source subpopulation (Blanco-Moreno, Chamorro, Masalles, Recasens, \& Sans, 2004; Petit et al., 2013).

The proportion of a seed dispersing outside the source sub-population's home section was trailed at both $4 \%$ and $10 \%$ of annual seed production, with $2 \%$ of this seed-loss directed into each corner section, and the remaining $92 \%$ into the four immediately adjacent sections. Header seed spread is assumed not to occur (Table 2).

\section{EVOLUTION OF RESISTANCE}

The model was run-in for 10 years prior to adding a single herbicide resistant allele to a weed plant in the sub-population in the central section of the SOMER model. This run-in was used to establish a realistically variable population distribution across the 1.17 hectare test area (Blanco-Moreno, Chamorro, \& Sans, 2006). The average weed density for the entire area was maintained at 125 weeds $\mathrm{m}^{-2}$, however by year 10 there was a density range from 1:1000 $\mathrm{m}^{-2}$ with weak development of patches (Figure 3). A single resistant allele was also added to

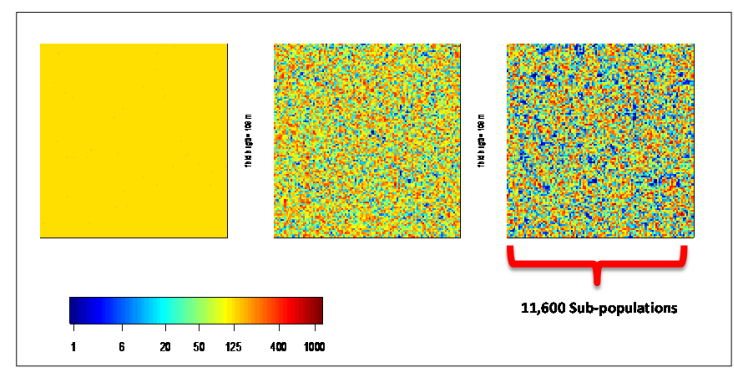

Figure 3. Changes in weed numbers per section during the run in period. the non-spatially modelled population at year 11 .

A field size of 1.17 hectare $(108 \mathrm{~m}$ by $108 \mathrm{~m})$ was selected as large enough to incorporate the significant annual spread of $L$. rigidum pollen and seeds. An area slightly larger than one hectare was chosen to allow a header width of $12 \mathrm{~m}$ to be incorporated into later simulations.

\section{RESULTS}

Incorporating a spatial constraint into resistance modelling slowed the buildup of herbicide resistance. In the nonspatial model numbers of resistant weeds increased from 10 per hectare to 100 per hectare in just one year. In comparison the SOMER spatial model with $10 \%$ annual seed dispersal took 3 years to increase average weed numbers from 10 per hectare to 100 per hectare (Figure 4). A drop in seed dispersal rates from $10 \%$ to $4 \%$ resulted in a further delay in resistance evolution, when it took four years for average weed numbers to increase from 10 per hectare to 100 per hectare.

Realistic depictions of resistance spread across a field were also generated (Figure 5).

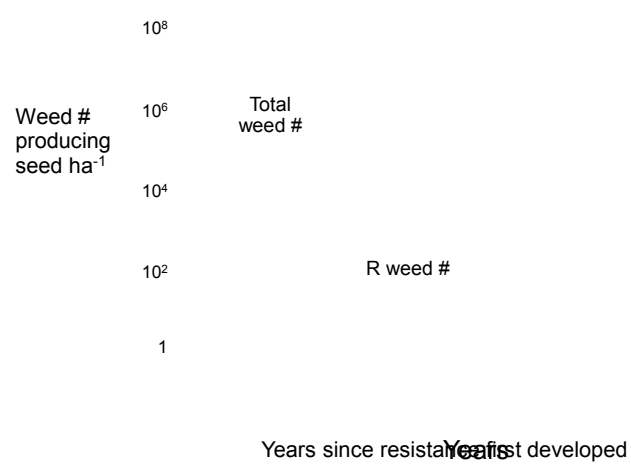

Figure 4. The solid lines in this diagram show the total number of weeds /ha estimated by each of three models on a log scale. The dashed lines show the number of herbicide resistant weeds in each simulation. 
Somerville and Renton, Does adding a spatial component to a herbicide resistance population model improve understanding and predictions of the build-up of herbicide resistance over time?

\section{DISCUSSION}

All three models started with the same level of herbicide resistance, in the same sized field. Numbers of weeds increased much more rapidly in the non-spatial model where numbers of resistant weeds followed an exponential growth curve (linear on the log scale). This meant that one extra year of herbicide control was gained for every one tenth reduction in the initial frequency of resistant genes, a result which seems unrealistic for some herbicides (Powles \& Yu, 2010). In contrast in the SOMER spatial model the increase in numbers of resistant weeds was much more gradual (Figure 4), due the earlier spatial constraints on density reducing the more rapid increase in weed numbers in the non-spatial model. In addition, the

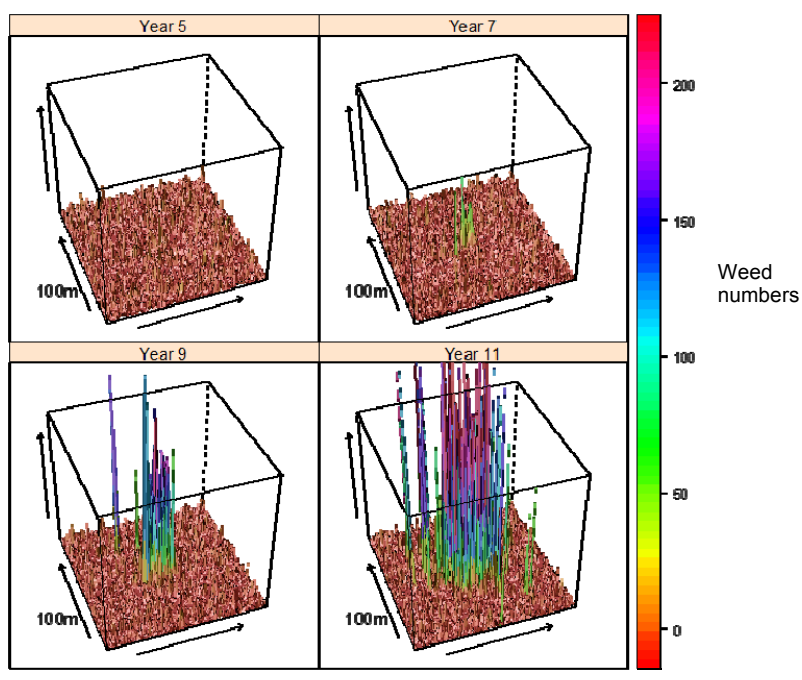

Figure 5. Weeds per $\mathrm{m}^{2}$ in each of the sections of the wheat field. graphical representations possible with this system of modelling produced informative graphs; showing growth in resistance, as well and changes in weed numbers, and visually realistic images of increases in weed numbers in the field. This may help address the short-term management focus of some growers (Norsworthy et al., 2012).

Further research could incorporate the use of harvest weed seed control, although adding the seed spreading actions of a harvester may require the modelling of a larger area, possibly incorporating larger sub-population sizes. In addition as one of the two years of data from Knowles and Ghosh (1968) contained directional wind mediated pollen spread it should be possible to incorporate this effect into the pollen spread calculations.

\section{ACKNOWLEDGEMENTS}

Special thanks to staff and students in the AHRI team at UWA, as well as my fellow modellers in Dr Renton's study group.

\section{REFERENCES}

Aguiar, M. R., \& Sala, O. E. (1997). Seed distribution constrains the dynamics of the Patagonian steppe. Ecology, 78(1), 93-100.

Blanco-Moreno, J. M., Chamorro, L., Masalles, R. M., Recasens, J., \& Sans, F. X. (2004). Spatial distribution of Lolium rigidum seedlings following seed dispersal by combine harvesters. Weed Research, 44(5), 375387. doi:10.1111/j.1365-3180.2004.00412.x

Blanco-Moreno, J. M., Chamorro, L., \& Sans, F. X. (2006). Spatial and temporal patterns of Lolium rigidumAvena sterilis mixed populations in a cereal field. Weed Research, 46(3), 207-218.

Boutsalis, P., Gill, G. S., \& Preston, C. (2012). Incidence of herbicide resistance in rigid ryegrass (Lolium rigidum) across southeastern Australia. Weed Technology, 26(3), 391-398.

Fenner, M. (1985). Seed ecology: Springer Science \& Business Media.

Humston, R., Mortensen, D. A., \& Bjornstad, O. N. (2005). Anthropogenic forcing on the spatial dynamics of an agricultural weed: the case of the common sunflower. Journal of Applied Ecology, 42(5), 863-872. doi:10.1111/j.1365-2664.2005.01066.x

Knowles, R. P., \& Ghosh, A. N. (1968). Isolation requirements for smooth bromegrass, Bromus inermis Leyss., as determined by a genetic marker. Agronomy Journal, 60(4), 371-374. 
Somerville and Renton, Does adding a spatial component to a herbicide resistance population model improve understanding and predictions of the build-up of herbicide resistance over time?

Lacoste, M. (2014). RIM 2013: default settings. Retrieved from Australian Herbicide Resistance Initiative \& School of Agricultural and Resource Economics, The University of Western Australia, Perth.: http://www.ahri.uwa.edu.au/files/files/1261 RIM 2013 Default settings 2014.pdf

Lacoste, M., \& Powles, S. (2014). Upgrading the RIM model for improved support of integrated weed management extension efforts in cropping systems. Weed Technology, 28(4), 703-720.

Llewellyn, R. S., D'Emden, F. H., Owen, M. J., \& Powles, S. (2009). Herbicide Resistance in Rigid Ryegrass $(<\mathrm{i}>$ Lolium rigidum $</ \mathrm{i}>)$ Has Not Led to Higher Weed Densities in Western Australian Cropping Fields. Weed Science, 57(1). doi:10.1614/WS-08-067.1

Malone, J., Boutsalis, P., Baker, J., \& Preston, C. (2014). Distribution of herbicide-resistant acetyl-coenzyme A carboxylase alleles in Lolium rigidum across grain cropping areas of South Australia. Weed Research, 54(1), 78-86.

Morrison, I. N., Nawolsky, K. M., Entz, M. H., \& Smith, A. E. (1991). Differences among certified wheat seedlots in response to trifluralin. Agronomy Journal, 83(1), 119-123.

Norsworthy, J. K., Ward, S. M., Shaw, D. R., Llewellyn, R. S., Nichols, R. L., Webster, T. M., . . Barrett, M. (2012). Reducing the risks of herbicide resistance: Best management practices and recommendations. Weed Science, 60, 31-62. doi:10.1614/WS-D-11-00155.1

Owen, M. J., Martinez, N. J., \& Powles, S. B. (2014). Multiple herbicide-resistant Lolium rigidum (annual ryegrass) now dominates across the Western Australian grain belt. Weed Research, 54(3), 314-324.

Petit, S., Alignier, A., Colbach, N., Joannon, A., Le Coeur, D., \& Thenail, C. (2013). Weed dispersal by farming at various spatial scales. A review. Agronomy for Sustainable Development, 33(1), 205-217. doi:10.1007/s13593-012-0095-8

Powles, S., \& Yu, Q. (2010). Evolution in action: Plants resistant to herbicides. In S. Merchant, W. R. Briggs, \& D. Ort (Eds.), Annual Review of Plant Biology, Vol 61 (Vol. 61, pp. 317-347). Palo Alto: Annual Reviews.

R Core Team. (2014). R: A language and environment for statistical computing. Retrieved from http://www.Rproject.org/

Renton, M. (2009). The weeds fight back: Individual-based simulation of evolution of polygenic resistance to herbicides. Paper presented at the 18th World IMACS Congress and MODSIM09 International Congress on Modelling and Simulation. Modelling and Simulation Society of Australia and New Zealand and International Association for Mathematics and Computers in Simulation.

Renton, M. (2011). How much detail and accuracy is required in plant growth sub-models to address questions about optimal management strategies in agricultural systems? AoB plants, 2011, plr006-plr006. doi:10.1093/aobpla/plr006

Renton, M., Diggle, A., Manalil, S., \& Powles, S. (2011). Does cutting herbicide rates threaten the sustainability of weed management in cropping systems? Journal of theoretical biology, 283(1), 14-27.

Walsh, M., Newman, P., \& Powles, S. (2013). Targeting weed seeds in-crop: A new weed control paradigm for global agriculture. Weed Technology, 27(3), 431-436. doi:10.1614/WT-D-12-00181.1 